\title{
IMPLIKATUR PERCAKAPAN DALAM KOMUNIKASI ANTARSISWA \\ DI SMP N 1 SAWAN SINGARAJA
}

\author{
I Nyoman Adi Susrawan \\ Program Studi Pendidikan Bahasa dan Sastra Indonesia \\ Fakultas Keguruan dan Ilmu Pendidikan \\ Universitas Mahasaraswati Denpasar \\ Email : adisusrawan1988@gmail.com
}

\begin{abstract}
ABSTRAK
Penelitian ini merupakan penelitian deskriptif kualitatif yang bertujuan untuk mendeskripsikan bentuk lingual implikatur percakapan yang muncul dalam komunikasi antarsiswa di SMP N 1 Sawan dan mendesripsikan proses terjadinya implikatur percakapan dalam komunikasi antarsiswa di SMP N 1 Sawan. Dalam penelitian ini, metode yang digunakan untuk pengumpulan data adalah metode observasi, wawancara, dan rekaman. Data yang telah terkumpul selanjutnya dianalisis melalui tiga tahap model alir, yaitu reduksi data, penyajian data, dan verifikasi data. Hasil penelitian ini menunjukkan bahwa ada tiga bentuk lingual yang ditemukan, yaitu bentuk lingual perintah, bentuk lingual berita dan bentuk lingual kalimat tanya. Dipilihnya bentuk lingual itu dalam percakapan antarsiswa di SMP N 1 Sawan dengan tujuan agar penutur maupun mitra tutur tidak merasa tersinggung. Selain itu, munculnya bentuk lingual seperti bentuk lingual kalimat perintah, berita dan kalimat tanya dalam percakapan disebabkan karena faktor kedekatan atau keakraban yang kemudian mempengaruhi suatu bentuk komunikasi yang terjadi. Berkaitan dengan impikatur percakapan yang terjadi dalam komunikasi antarsiswa di SMP N 1 Sawan terdapat enam macam implikatur percakapan. Keenam macam implikatur percakapan itu adalah mengajak menolak, mengejek, menyuruh, meminta, dan menginformasikan fakta. Hasil penelitian ini diharapkan dapat dijadikan sebagai dasar dalam menangkap maksud tersirat yang hendak disampaikan oleh penutur kepada mitra tutur.
\end{abstract}

Kata kunci : Implikatur percakapan.

\begin{abstract}
This descriptive qualitative research aimed at describing the form and process of linguistic implicature form which exists in the communication among students of SMP N 1 Sawan. The method of data collection in this research was observation interview and recording. The data gathered were then analyzed through three phase namely data reduction, data display, and data verification. The result of this study showed that there were three forms of language functions namely imperatives or command, reporting and questioning. The reason of choosing those forms of language function was to avoid misunderstanding among speakers or hearers so that no one will get offended. Besides, the use of imperatives, report, and questions was due to the factor of familiarity and intimacy between speakers. In relation to conversational implicature, the students of SMP N 1 Sawan use six kinds of implicature. Those are, asking, rejecting, mocking, commanding, ordering, and
\end{abstract}


informing facts. Hopefully, the result of this research can give contribution in understanding the implied meaning of the speaker to the hearer.

Keywords: conversational implicature

\section{Pendahuluan}

Manusia pada hakikatnya adalah mahkluk sosial. Manusia sebagai mahkluk sosial senantiasa mengadakan komunikasi dengan orang-orang yang ada di dalam masyarakat. Terjadinya komunikasi antar manusia itu ditandai dengan orang yang menjadi sumber informasi (komunikator) dan adanya orang yang menjadi penerima informasi (komunikan). Suatu komunikasi dikatakan berhasil jika pesan yang disampaikan komunikator dapat dipahami komunikan persis sama seperti yang dimaksud komunikator tersebut. Komunikasi menggunakan bahasa sebagai mediumnya.

Melalui bahasa manusia menyatakan perasaan dan pendapat, bahkan dengan bahasa, manusia dapat berpikir dan bernalar. Bahasa merupakan suatu alat yang paling utama untuk berkomunikasi antar manusia. Dengan kata lain, manusia akan sangat tergantung pada suatu bahasa dan mengingat juga bahwa manusia adalah makhluk sosial, makhluk yang tidak dapat hidup tanpa orang lain. Dalam hal ini tentulah antarmanusia akan terjadi suatu interaksi (komunikasi) untuk berbagai tujuan. Bahasa yang digunakan oleh manusia bukanlah bahasa yang statis, tetapi bahasa yang selalu berkembang sesuai kebutuhan manusia sebagai penggunanya.

Berbagai fenomena yang muncul di dalam kehidupan praktis akan berpengaruh besar terhadap suatu bahasa. Sering kali kaidah-kaidah bahasa yang disepakati mengalami stagnasi menghadapi fenomena penggunaan bahasa pada tataran praktis. Pengkajian suatu bahasa pada tataran struktural saja sering tidak menghasilkan suatu kajian yang maksimal. Kondisi praktis penggunaan bahasa sering "keluar" dari kaidahkaidah struktural, tetapi proses komunikasi yang terjadi tidak menemui suatu kendala dan justru menghasilkan suatu komunikasi yang lebih efektif dan efisien. Hal itulah yang mendorong suatu kajian terhadap suatu bahasa tidak hanya dari sudut pandang struktural saja, melainkan 
harus dikaitkan dengan aspek-aspek di luar struktur bahasa.

Salah satu kajian bahasa yang mampu mengakomodasi aspek-aspek di luar bahasa dalam pengkajiannya adalah pragmatik maupun analisis wacana. Dalam dua bidang kajian ini, pengkajian suatu bahasa dengan melibatkan aspek-aspek di luar bahasa yang turut serta mamberi makna dalam suatu komunikasi. Melibatkan aspek-aspek di luar bahasa sangatlah tepat ketika melihat fenomena penggunaan bahasa pada tataran praktis yang cukup beragam.

Dalam suatu komunikasi, di dalamnya dapat dipastikan akan terjadi suatu percakapan. Percakapan pada hakikatnya adalah peristiwa berbahasa lisan antara dua orang partisipan atau lebih yang pada umumnya terjadi dalam suasana santai. Percakapan merupakan wadah yang memungkinkan terwujudnya prinsipprinsip kerjasama dan sopan santun dalam peristiwa berbahasa. Untuk itu perlu memahami implikatur percakapan, agar apa yang diucapkan dapat dipahami oleh lawan tutur. Salah satu bagian dari kajian pragmatik adalah implikatur percakapan.
Percakapan yang terjadi antar pelibat sering mengandung maksudmaksud tertentu yang berbeda dengan struktur bahasa yang digunakan. Dalam kondisi tersebut suatu penggunaan bahasa memungkinkan mempunyai maksud-maksud yang tersembunyi di balik penggunaan bahasa secara struktural. Pada kondisi seperti itulah suatu kajian implikatur percakapan mempunyai peran yang tepat untuk mengkaji suatu penggunaan bahasa.

Dalam penelitian ini akan dipaparkan suatu kajian implikatur percakapan yang terjadi di dalam suatu kelompok sosial yang berada di lingkungan sekolah, yaitu SMP N 1 Sawan. Dalam komunikasi antarsiswa dimungkinkan muncul suatu percakapan yang mengandung maksud-maksud tertentu yang terkadang berbeda dengan apa yang terkandung dalam pertuturan yang muncul. Dalam hal ini pengkajian dari sudut implikatur percakapan dimungkinkan dapat memperjelas proses komunikasi yang terjadi. Adapun masalah yang dikaji dalam penelitian ini adalah Bagaimanakah bentuk lingual implikatur percakapan yang muncul 
dalam komunikasi antarsiswa di SMP N 1 Sawan?, (2) Jenis implikatur percakapan apa sajakah yang muncul dalam komunikasi antarsiswa di SMP N 1 Sawan?

\section{Metode Penelitian}

Penelitian ini merupakan penelitian deskriptif kualitatif yang bertujuan untuk mendeskripsikan bentuk lingual implikatur percakapan yang muncul dalam komunikasi antarsiswa di SMP N 1 Sawan dan mendesripsikan proses terjadinya implikatur percakapan dalam komunikasi antarsiswa di SMP N 1 Sawan. Dalam penelitian ini, metode yang digunakan untuk pengumpulan data adalah metode observasi, wawancara, dan rekaman. Data yang telah terkumpul selanjutnya dianalisis melalui tiga tahap model alir, yaitu reduksi data, penyajian data, dan verifikasi data.

\section{Pembahasan}

Data yang akan dikaji dalam penelitian ini adalah data dari sudut implikatur percakapan yang diambil dari percakapan yang terjadi atarasiswa SMP N 1 Sawan. Adapun data yang diperoleh adalah sebagai berikut. Dalam penelitian ini, peneliti lebih memfokuskan bentuk lingual pada tataran makna kalimat, karena kalimat telah mengandung proposisi yang memberikan sumbangan langsung kepada penutur dalam menyampaikan implikatur percakapan. Istilah bentuk lingual di sini adalah bentuk lingual yang bermuatan implikatur percakapan.

\subsection{Bentuk lingual implikatur percakapan berdasarkan pada tataran makna kalimat}

Berdasarkan maknanya, kalimat dapat dibedakan menjadi lima macam, yaitu kalimat berita (deklaratif), kalimat perintah (imperatif), kalimat tanya (interogatif), kalimat seru (interjektif), dan kalimat emfatik.

Data 1 Bentuk lingual kalimat berita

\begin{tabular}{|c|c|}
\hline $\begin{array}{l}\text { Luh } \\
\text { Juliani }\end{array}$ & $\begin{array}{l}\text { : "Hei temen-teman } \\
\text { tugasnya belum selesai } \\
\text { nich, soal nomor } 4 \\
\text { belum aku kerjakan" (IP } \\
\text { 1) }\end{array}$ \\
\hline Edi & $\begin{array}{l}\text { "Baru sampai nomor } \\
\text { berapa kamu kerjakan?" }\end{array}$ \\
\hline $\begin{array}{l}\text { Luh } \\
\text { Juliani }\end{array}$ & $\begin{array}{l}\text { :Nich aku masih } \\
\text { mengerjakan } \\
\text { nomor 3" }\end{array}$ \\
\hline Edi & $\begin{array}{l}\text { (Bergegas mengambil } \\
\text { buku dan mengerjakan } \\
\text { soal nomor } 4) .\end{array}$ \\
\hline
\end{tabular}

Konteks tuturan: percakapan terjadi ketika Luh Juli dengan teman- 
temanya membuat tugas kelompok di dalam kelas. Pada data yang pertama ini terdapat suatu implikatur percakapan. Implikatur tersebut terlihat pada ujaran yang disampaikan (Luh Juli). Ujaran tersebut menghadirkan suatu bentuk pertuturan yang bersifat infomatif saja, yaitu hanya memberitahukan bahwa tugasnya belum selesai, dan lebih lanjut Luh Juli mengatakan bahwa dia sedang mengerjakan soal nomor 3 dan soal nomor 4 belum ada yang mengerjakan. Reaksi dari Edi selaku mitra tutur, dia langsung mengerjakan soal nomor 4. Dalam percakapan tersebut terjadi suatu proses implikasi pertuturan, pihak penutur yang sebenarnya bermaksud menyuruh lawan tutur untuk melakukan sesuatu, tidak dinyatakan secara langsung menyuruh, tetapi diimplikasikan dibalik tuturan yang bersifat informatif tersebut. Dikaitkan dengan jenis implikatur dari Grice, implikatur percakapan tersebut termasuk implikatur konvensional, karena pihak lawan tutur dapat memahami maksud penutur.

\section{Data 2 Bentuk lingual kalimat berita}

\begin{tabular}{llll}
\hline Nova & : & "Ntar habis jam \\
Darmayasa & pertama kita ke \\
& kantin yuk" & \\
\hline Juliani & : & "Orang ntar jam \\
& kedua ibu Luh \\
& Darmiati langsung \\
& ngajar" (IP 2) \\
\hline Widia & : & "Ngak lama kok, \\
& cuma mau beli \\
& minum saja" \\
\hline
\end{tabular}

Konteks tuturan: percakapan terjadi ketika jam pelajaran pertama akan dimulai. Ujaran Nova merupakan ajakan, dan jawaban untuk pertanyaan itu biasanya berupa penerimaan dan penolakan. Jawaban Juliani bisa kita pahami sebagai penolakan halus terhadap ajakan Nova. Dalam hal ini, Juli tidak menggunakan secara langsung seperti "ah malas/tidak mau", tetapi dengan penolakan tidak langsung tadi. Ini berarti bahwa penolakan itu terimplikasi di dalam ujaran "Orang ntar jam kedua ibu Luh Darmiati langsung ngajar" sementara ujarannya sendiri tidak berbentuk penolakan.

Data 3 Bentuk lingual kalimat perintah

\begin{tabular}{|c|c|c|}
\hline Sri & : & $\begin{array}{l}\text { "Ingat buku yang isinya } \\
\text { 50, ini uangnya" (IP 3) }\end{array}$ \\
\hline Ern & 0 & "Ya" (keluar) \\
\hline
\end{tabular}




\begin{tabular}{ll}
\hline Eka $\quad$ : "Aku nitip, belikan aku \\
\\
TV" (Sambil tertawa) \\
(IP 4) \\
\hline
\end{tabular}

Konteks tuturan: percakapan terjadi ketika Erna akan pergi ke koperasi sekolah untuk membeli sesuatu, tiba-tiba Sri memanggil Erna untuk meminta membelikan buku yang sebelumnya sudah sempat mereka bicarakan. Ada beberapa implikatur dalam percakapan tersebut. Yang pertama, suatu maksud meminta bantuan untuk dibelikan buku, yang hanya terealisasikan dalam bentuk tuturan "Buku yang isinya 50, ini uangnya." dapat tertangkap maksudnya oleh mitra tutur. Dalam hal ini, percakapan yang terjadi sudah didasari suatu praanggapan, bahwa penutur (Erna) tahu mitra tutur (Sri) memang menginginkan buku itu, tetapi karena tidak sempat keluar membeli, akhirnya meminta tolong pada penutur (Erna) yang kebetulan keluar pada saat itu. Di dalam percakapan ini juga ditemukan sebuah tuturan yang mengandung implikatur percakapan yang lain. Pada ujaran yang dilontarkan oleh Eka cukup jelas apabila diartikan secara harfiah, yaitu dia meminta tolong kepada Erna untuk dibelikan TV. Implikatur percakapan yang muncul jika dikaitkan dengan konteks yang ada saat itu hanyalah sebuah candaan, karena memang permintaan itu sangat tidak mungkin untuk direalisasikan.

\section{Data 4 Bentuk lingual kalimat perintah}

\begin{tabular}{|c|c|c|}
\hline $\begin{array}{l}\text { Ari } \\
\text { Susanti }\end{array}$ & : & $\begin{array}{l}\text { "Mejanya } \\
\text { supaya } \\
\text { rapi" }\end{array}$ \\
\hline $\begin{array}{l}\text { Nova } \\
\text { Darsana } \\
\end{array}$ & : & $\begin{array}{l}\text { "Orang aku sendiri } \\
\text { bekerja" (IP 5) }\end{array}$ \\
\hline Wisnu & : & (Diam) \\
\hline
\end{tabular}

Konteks tuturan: percakapan terjadi ketika membersihkan ruangan kelas. Percakapan yang terjadi pada data ini termasuk ke dalam implikatur percakapan nonkonvensional. Dalam hal ini, konteks situasi sangat berpengaruh terhadap munculnya percakapan tersebut. Pada percakapan ini, diartikan secara harfiah, merupakan sebuah tuturan yang bersifat informatif saja. Namun, ketika dikaitkan dengan konteks situasi yang ada, bahwa saat itu meja harus segera dipindahkan, dan di ruangan itu hanya ada tiga orang, yaitu Ari, Nova, dan Wisnu. Wisnu ketika itu tidak membantu memindahkan meja. percakapan itu dapat diimplikasikan sebagai permintaan kepada Wisnu 
untuk segera membantu memindahkan meja tersebut.

\begin{tabular}{lll}
$\begin{array}{l}\text { Data } 5 \\
\text { Bentuk lingual kalimat } \\
\text { perintah }\end{array}$ & \\
\hline $\begin{array}{l}\text { Ferry } \\
\text { Kurniawan }\end{array}$ & $\begin{array}{l}\text { "Segera bersihkan } \\
\text { ruangan ini! keburu } \\
\text { sore" (IP 6) }\end{array}$ \\
\hline Diana & $: \begin{array}{l}\text { (Mengambil sapu } \\
\text { Agustini }\end{array}$ & $\begin{array}{l}\text { kemudian } \\
\text { membersihkan } \\
\text { ruangan) }\end{array}$ \\
\hline
\end{tabular}

Implikatur percakapan di atas diungkapkan dengan bentuk lingual kalimat perintah. Dalam konteks tersebut, jika diartikan secara harfiah akan sulit diterima, karena waktu saat itu masih pagi, dan waktu sore masih jauh. Tuturan tersebut lebih mempunyai implikasi sebagai bentuk candaan maupun sebagai bentuk sindiran karena tidak segera membersihkan ruangan.

\section{Data 6 Bentuk lingual kalimat berita}

\begin{tabular}{lll}
\hline Budi & : & "Mau ke mana Di? \\
Artawan & & \\
\hline Adi & : & "Isi perut" (IP 7) \\
\hline Budi & : & "cepat sedikit" \\
Artawan & & \\
\hline
\end{tabular}

Dalam percakapan tersebut terkandung suatu implikatur percakapan yang tergolong dalan suatu implikatur percakapan konvensional.
Implikatur tersebut terlihat pada dialog kedua. Dalam dialog tersebut terdapat suatu impliktur yang cukup mudah untuk ditangkap hanya dengan memaknai secara harfiah kata-kata yang digunakan dalam tuturan tersebut. Walaupun tuturan tersebut cukup mudah untuk dipahami, tetapi tetap termasuk suatu implikatur percakapan, karena maksud dari penutur meminta waktu untuk makan, tersembuyi (terimplikasi) dalam tuturan tersebut.

\section{Data 7 Bentuk lingual kalimat berita}

\begin{tabular}{|c|c|c|}
\hline $\begin{array}{l}\text { Vemi Uda } \\
\text { Cahyani }\end{array}$ & : & $\begin{array}{l}\text { (Datang) "Bagimana } \\
\text { sudah siap?" }\end{array}$ \\
\hline $\begin{array}{l}\text { Ari } \\
\text { Susanti }\end{array}$ & : & "Siap" \\
\hline $\begin{array}{l}\text { Vemi Uda } \\
\text { Cahyani }\end{array}$ & : & $\begin{array}{l}\text { "Teman-teman } \\
\text { mana ya?" }\end{array}$ \\
\hline $\begin{array}{l}\text { Ari } \\
\text { Susanti }\end{array}$ & : & $\begin{array}{l}\text { "Masih istirahat di } \\
\text { kantin" }\end{array}$ \\
\hline $\begin{array}{l}\text { Vemi Uda } \\
\text { Cahyani }\end{array}$ & : & $\begin{array}{l}\text { "Mau kemana kamu } \\
\text { Ri?" }\end{array}$ \\
\hline $\begin{array}{l}\text { Ari } \\
\text { Susanti }\end{array}$ & & $\begin{array}{l}\text { "Ke kantin, kamu } \\
\text { mau ikut?" }\end{array}$ \\
\hline $\begin{array}{l}\text { Vemi Uda } \\
\text { Cahyani }\end{array}$ & : & $\begin{array}{l}\text { "Orang sudah bel } \\
\text { masuk" (IP 8) }\end{array}$ \\
\hline $\begin{array}{l}\text { Ari } \\
\text { Susanti }\end{array}$ & & $\begin{array}{l}\text { "Sebentar aja" } \\
\text { (sambil pergi menuju } \\
\text { kantin) }\end{array}$ \\
\hline
\end{tabular}

Konteks tuturan terjadi di dalam kelas. Pada percakapan di atas terdapat implikatur konvensional, yakni pada saat (Vemi) berkata "Orang sudah 
bel masuk". Dalam hal ini, terjadi suatu proses implikasi pertuturan, pihak penutur (Vemi) yang sebenarnya bermaksud melarang lawan tutur (Ari) untuk tidak keluar kelas, tidak secara langsung melarang, tetapi diimplikasikan dibalik tuturan yang bersifat informatif. Selain itu, dalam percakapan ini ditemukan juga adanya praanggapan. Dalam hal ini, dua pelibat sudah saling mengetahui peran masing-masing dalam kegiatan kelompok, yang satu menjadi penyaji pertama dan yang satunya menjadi penyaji kedua. Praanggapan terjadi ketika tiba-tiba (Vemi) datang dan hanya melontarkan kata "bagaimana sudah siap?" dan mitra tutur (Ari) menjawab dengan tuturan "siap". Proses tuturan seperti ini akan sangat sulit diikuti apabila tidak mempunyai dasar pengetahuan bersama (praanggapan) antar penutur dan mitra tutur.

Data 8 Bentuk lingual kalimat tanya

\begin{tabular}{ll}
\hline Luh De : & "Temen-temen ada \\
& tugas nich dari buk \\
& Darmiati, kerjakan \\
& soal di LKS, minggu \\
& depan dikumpul!" \\
\hline Leona : & "Buih, lagi ngasi \\
& tugas, mantap. Luh, \\
& nanti tugas ini kita \\
& kerjakan di rumahmu \\
& saja yuk" \\
\hline Luh De $\quad:$ & "Adikku sakit, gimana \\
\hline
\end{tabular}

\begin{tabular}{ll}
\hline & $\begin{array}{l}\text { kalau di rumahmu aja } \\
\text { kita buat?" (IP 9) }\end{array}$ \\
\hline Leona $\quad$ : "Boleh" \\
\hline
\end{tabular}

Kontek tuturan: percakapan terjadi di dalam kelas, ketika itu si Luh De baru datang dari ruangan guru kemudian memberikan informasi bahwa ada tugas dari guru Sejarah. Implikatur percakapan tampak pada ujaran Luh De "Adikku sakit, gimana kalau di rumahmu aja kita buat?" tuturan tersebut mengadung informasi penolakan Luh De terhadap ajakan Leona. Bentuk penolakan yang diujarkan oleh penutur Luh De tidak dilakukan secara terang-terangan atau langsung, melainkan dengan cara taklangsung yakni dengan melontarkan kalimat bentuk lingual tanya (interogatif). Hal ini dilakukan oleh penutur dengan tujuan agar orang yang mengajak atau menawari sesuatu tidak tersinggung.

Sesuai dengan analis data tersebut, maka dapat ditarik sebuah simpulan bahwa bentuk lingual implikatur percakapan yang muncul dalam komunikasi antar siswa di SMP N 1 Sawan di dominasi oleh bentuk lingual kalimat berita, bentuk lingual kalimat perintah dan bentuk lingual kalimat tanya (interogatif) . Bentuk 
lingual berupa kalimat seru (interjektif), dan kalimat emfatik tidak ditemukan dalam data ini. Bentuk lingual kalimat berita dapat diamati pada data $1,2,6,7$, kemudian data bentuk lingual kalimat perintah pada data 3, 4, dan 5 dan bentuk lingual kalimat tanya ditemukan pada data 8 .

\subsection{Implikatur percakapan dalam} komunikasi antarsiswa di SMP N 1 Sawan

Implikatur adalah implikasi pragmatik yang terkandung dalam satu bentuk lingual yang diujarkan penutur kepada mitra tutur dalam suatu percakapan. Dari hasil analisis data yang telah dilakukan, ditemukan adanya lima macam implikatur percakapan dalam komunikasi antarsiswa di SMP N 1 Sawan. Kelima macam implikatur percakapan itu adalah mengajak, menolak, mengejek, menyuruh, dan menginformasikan fakta. Masing-masing implikatur percakapan itu dipaparkan pada bagian berikut ini.

\section{Implikatur percakapan mengajak.}

Mengajak berarti meminta lawan tutur untuk bersama-sama melakukan sesuatu. Data yang menunujukkan implikatur percakapan mengajak dapat diamati pada kutipan berikut ini.

\begin{tabular}{ll}
\hline Nova & : "Ntar habis jam \\
Darmayasa & $\begin{array}{l}\text { pertama kita ke } \\
\text { kantin yuk" }\end{array}$ \\
\hline
\end{tabular}

Kutipan data 2

\begin{tabular}{ll}
\hline Leona : & "Buih, lagi ngasi \\
& tugas, mantap. Luh, \\
& nanti tugas ini kita \\
& kerjakan di rumahmu \\
& saja yuk" \\
Kutipan data 8
\end{tabular}

Kedua kutipan di atas merupakan implikatur percakapan mengajak yang ditandai dengan kata $y u k$ sebagai bentuk ajakan Nova kepada mitra tutur (Juliani) untuk pergi ke kantin maupun ajakan Leona untuk membuat tugas di rumahnya Luh De. Bentuk lingual yang digunakan oleh penutur dalam implikatur percakapan mengajak adalah bentuk lingual kalimat berita. Dipilihnya kalimat tanya untuk menyampaikan ajakan dalam tuturan ini adalah agar penutur terkesan tidak memaksakan kehendaknya kepada mitra tutur.

2. Implikatur percakapan menolak. Implikatur percakapan menolak dimaksudkan untuk tidak melaksanakan apapun yang dikehendaki oleh penutur kepada 


\begin{tabular}{lc} 
mitra tutur. & Data yang \\
menunjukkan & \multicolumn{1}{c}{ implikatur } \\
percakapan & menolak dapat \\
diamati pada data berikut ini. \\
\hline Juliani $\quad \begin{array}{l}\text { "Orang ntar jam } \\
\text { kedua ibu Luh } \\
\end{array}$ \\
& $\begin{array}{l}\text { Darmiati } \\
\text { langsung ngajar" }\end{array}$
\end{tabular}

Kutipan data 2

\begin{tabular}{ll}
\hline Vemi : "Orang sudah bel \\
masuk" \\
\hline Kutipan data 7 \\
\hline Luh : "Adikku sakit, \\
De $\begin{array}{l}\text { gimana kalau di } \\
\text { rumahmu aja kita } \\
\text { buat?" }\end{array}$ \\
\hline Kutipan data 8
\end{tabular}

Kutipan data 8

Ketiga ujaran tersebut mengandung implikatur percakapan menolak yang diungkapkan dengan bentuk lingual kalimat berita (deklaratif) pada kutipan data 2 dan kutipan 8 dan bentuk lingual kalimat tanya pada kutipan 8. Dipilihnya bentuk lingual kalimat berita dan bentuk lingual kalimat tanya untuk menolak ajakan penutur dilakukan oleh penutur dengan tujuan agar mitra tutur tidak merasa tersinggung.

\section{Implikatur percakapan mengejek.}

Selain implikatur menolak implikatur percakapan mengejek juga ditemukan dalam komunikasi antarsiswa di SMP N 1 Sawan. Implikatur percakapan mengejek dikemukakan oleh penutur dengan maksud bercanda dan ada juga yang diungkapkan dengan maksud menyindir. Implikatur percakapan mengejek ataupun menyindir diungkapkan dengan bentuk lingual kalimat perintah. Dipilihnya bentuk lingual perintah untuk menyindir ataupun mengejek temannya karena kedekatan atau keakraban penutur dan mitra tutur. Data ini dapat ditemukan pada data 5.

\begin{tabular}{lll}
\hline Ferry & : & "Segera \\
Kurniawan & $\begin{array}{l}\text { bersihkan } \\
\text { ruangan } \\
\text { keburu sore" ini! }\end{array}$ \\
\hline
\end{tabular}

Kutipan data 5

4. Implikatur

percakapan

menyuruh.

Implikatur menyuruh dilakukan oleh penutur kepada mitra tutur dengan tujuan agar mitra tutur mau melakukan sesuatu untuk kepentingan dirinya maupun orang lain. Data yang menunjukkan implikatur percakapan menyuruh dapat diamati pada data 3, 4, 5 .

\begin{tabular}{llrr}
\hline Sri : & "Ingat buku yang \\
& $\begin{array}{l}\text { isinya } \\
\text { uangnya" }\end{array}$ & \\
& & \\
\hline
\end{tabular}

Kutipan data 3 


\begin{tabular}{lll}
\hline Ari & $:$ & "Mejanya \\
Susanti & $\begin{array}{l}\text { digeser, } \\
\text { supaya } \\
\text { rapi" }\end{array}$ & kelihatan \\
\hline
\end{tabular}

Kutipan data 4

\begin{tabular}{lll}
\hline Ferry & $:$ & "Segera \\
Kurniawan & $\begin{array}{l}\text { bersihkan } \\
\text { ruangan ini! } \\
\text { keburu sore" }\end{array}$ \\
\hline
\end{tabular}

Kutipan data 5

Dalam peristiwa percakapan ini penutur lebih cenderung menggunakan bentuk lingual perintah dari pada bentuk lingual tanya. Dipilihnya bentuk lingual perintah oleh penutur kepada mitra tutur adalah karena keakraban diantara mereka.

\section{Implikatur percakapan meminta}

\begin{tabular}{ll}
\hline Luh & "Hei temen-teman \\
Juliani & tugasnya belum \\
& selesai nich, soal \\
& nomor 4 belum aku \\
& kerjakan" \\
\hline
\end{tabular}

Kutipan data 1

Implikatur percakapan meminta pada percakapan siswa di SMP N 1 Sawan dinyatakan dalam bentuk lingual yang berupa berita (deklaratif). Dipilihnya bentuk lingual berita (deklaratif) dalam percakapan tersebut dilakukan dengan tujuan agar mitra tutur tidak tersinggung. Ujaran pada kutipan di tersebut jelas menginformasikan bahwa soal nomor 4 belum ada yang mengerjakan dan sekaligus meminta lawan tutur untuk segera mengerjakannya.

6. Implikatur percakapan menginformasikan fakta.

Implikatur percakapan menginformasikan fakta cukup dominan dalam peristiwa percakapan antarsiswa di SMP N 1 sawan. IP ini digunakan penutur untuk memberitahukan atau menyampaikan informasi kepada penutur. Karena sifatnya memberitahukan atau menginformasikan fakta maka ia selalu didukung oleh kalimat berita. Data terkait dengan implikatur percakapan menginformasikan fakta dapat ditemukan pada data berikut ini.

\begin{tabular}{ll}
\hline Luh & : "Hei temen-teman \\
Juliani & $\begin{array}{l}\text { tugasnya belum } \\
\text { selesai nich, soal } \\
\text { nomor 4 belum aku } \\
\text { kerjakan" }\end{array}$ \\
& \\
\hline Kutipan data 1 & \\
\hline Nova $\quad: \begin{array}{l}\text { "Orang aku sendiri } \\
\text { bekerja" }\end{array}$ &
\end{tabular}

Kutipan data 4

Adi : "Isi perut"

Kutipan data 6 


\begin{tabular}{ll}
\hline Vemi & "Orang sudah bel \\
Uda & masuk" \\
Cahyani & \\
\hline Kutipan data 7 &
\end{tabular}

\begin{tabular}{ll}
\hline Luh De : & "Temen-temen ada \\
& tugas nich dari buk \\
& Darmiati, kerjakan \\
& soal di $\quad$ LKS, \\
& minggu $\quad$ depan \\
& dikumpul!" \\
\hline
\end{tabular}

Kutipan data 8

$\begin{array}{lr}\text { Kutipan data pertama } \\ \text { bermaksud } & \text { untuk }\end{array}$

menginformasikan bahwa tugasnya

belum selesai. Kutipan data

keempat menginformasikan bahwa

Nova saja yang bekerja sedangkan

teman yang lainnya tidak ikut

bekerja. Ujaran Adi pada kutipan

keenam bermaksud

menginformasikan bahwa ia mau

makan di kantin. Selanjutnyan,

pada ujaran Vemi "Orang sudah

bel masuk" yang bermaksud untuk

menginformasikan bahwa kepada

lawan tuturnya untuk tidak pergi ke

kantin karena bel masuk sudah berbunyi. Ujaran dari Luh De:

"Temen-temen ada tugas nich dari

buk Darmiati, kerjakan soal di

LKS, minggu depan dikumpul!"

kutipan data kedelapan juga

bermaksud

untuk menginformasikan kepada temantemannya bahwa ada tugas baru yang harus dikerjakan.

\section{Penutup}

\subsection{Simpulan}

Berdasarkan analisis dan pembahasan hasil penelitian tentang implikatur percakapan yang terjadi dalam komunikasi antarsiswa di SMP N 1 Sawan yang telah diuraikan sebelumnya, makasimpulan yang dapat diampil dalam penelitian ini adalah sebagai berikut.

1) Ada tiga bentuk lingual yang ditemukan dalam penelitian ini, yaitu bentuk lingual perintah, bentuk lingual berita dan bentuk lingual kalimat tanya. Dipilihnya bentuk lingual itu dalam percakapan antarsiswa di SMP N 1 Sawan dengan tujuan agar penutur maupun mitra tutur tidak merasa tersinggung. Selain itu, munculnya bentuk lingual seperti bentuk lingual kalimat perintah, berita dan kalimat tanya dalam percakapan disebabkan karena faktor kedekatan atau keakraban 
akan mempengaruhi suatu bentuk komunikasi yang terjadi.

2) Berkaitan dengan impikatur percakapan yang terjadi dalam komunikasi antarsiswa di SMP N 1 Sawan terdapat enam macam implikatur percakapan. Keenam macam implikatur percakapan itu adalah mengajak menolak, mengejek, menyuruh, meminta, dan menginformasikan fakta.

\subsection{Saran}

Melalui penelitian ini peneliti ingin menyampaikan saran kepada mahasiswa atau dosen untuk melakukan kajian lebih mendalam mengenai implikatur percakapan khususnya percakapan yang terjadi antarsiswa di sekolah. Dengan memahami implikatur percakapan niscaya dapat menangkap maksud tersirat yang hendak disampaikan oleh mitra tutur.

\section{Daftar Pustaka}

Brown, G. dan Yule, G. 1996. Analisis Wacana. Jakarta: PT Gramedia Pustaka Utama.

Gunarwan, A. 2004. "Dari Pragmatik ke Pengajaran Bahasa" (Makalah Seminar Bahasa dan Sastra Indonesia dan Daerah). IKIP Singaraja.

Nababan, P.W.J. 1987. Ilmu Pragmatik: Teori dan Penerapannya. Jakarta: P2LPTK Depdikbud.

Soemarmo, M. 1994. PELLBA 7. Yogyakarta: Kanisius.

Wijana, I D. P. 1996. Dasar-dasar Pragmatik. Yogyakarta: Penerbit ANDI. 